\title{
Hypersensitivity Reactions to Biologicals: from Bench to Bedside
}

\author{
Aysegul Akarsu \\ Ozge Soyer \\ Bulent Enis Sekerel
}

\author{
Address \\ *Department of Pediatric Allergy, Hacettepe University School of Medicine, \\ 06100, Ankara, Turkey \\ Email: b_sekerel@yahoo.com
}

Published online: 18 January 2020

(C) Springer Nature Switzerland AG 2020

This article is part of the Topical Collection on Anaphylaxis

Keywords Anaphylaxis - Biologic agents · Hypersensitivity reactions · Monoclonal antibodies

\begin{abstract}
Purpose of Review Biologic agents are new treatment options for chronic inflammatory diseases and cancers. As a result of their unique mechanism of action, they are more effective and less toxic treatment option and their clinical usage is increasing. While they are more commonly used, various adverse effects have been observed including lifethreatening ones, including anaphylaxis. The aim of this review is to distinguish the anaphylaxis from other hypersensitivity reactions (HSR) and provide a management algorithm for the anaphylactic reactions induced by biological agents.

Recent Findings Many case reports and series have been published regarding anaphylaxis and other hypersensitivity reactions (concerning cytokine release syndrome, acute infusion-related reactions) due to biologic agents. Although acute treatment of HSR varies according to the clinical presentation, desensitization with the drug is the major management option for subsequent administrations in the case of anaphylactic reactions. Summary Anaphylaxis and other immediate onset hypersensitivity reactions are occasionally difficult to differentiate from each other, and mixed-type reactions may be observed. Immediate management of anaphylaxis includes discontinuation of infusion, immediate administration of adrenaline, antihistamines, corticosteroids, and other treatment options depending on the symptoms. After 30-120 min of the reaction, a blood sample for serum tryptase levels should be obtained and after 4-6 weeks skin testing with the culprit drug should be performed for decision of long-term management via either graded challenge or desensitization.
\end{abstract}




\section{Introduction}

Biologicals including cytokines, monoclonal antibodies (mAbs), and fusion proteins are new therapeutic agents. In 1984, the Nobel prize was awarded to the scientists who discovered the mAbs [1]. Today, over 150 biological agents have been approved for different types of cancers including lymphoma, leukemia, colorectal, breast, gastric and lung cancer, rheumatological diseases, and certain allergic and chronic inflammatory diseases, e.g., inflammatory bowel diseases, multiple sclerosis, and psoriasis $[2,3]$.

Nomenclature of biologic agents is based on rules. The first syllable of a biological is chosen randomly. The last syllable refers the mechanism of action: "-mab" for monoclonal antibody, "-cept" for soluble fusion receptors to Fc part of human immunoglobulin G1 (IgG1), and "-inib" for receptor antagonists. The penultimate syllable stands for the spices of origin: "-xi" indicates chimeric murine-human origin, "-zu" indicates humanized origin which contains complementarity determining regions of a mouse Ig onto human IgG1, and "-u" indicates fully human origin including human origin constant and variable regions. For monoclonal antibodies, the previous syllable indicates the target structure or target disease: "-li" for immune system, "ta" for tumor, "-ci" for cardiovascular system, "-vi" for virus, and "-ki" for interleukin [4,5]. For example, "omalizumab" refers to an immune system targeted, humanized monoclonal antibody or "etanercept" refers to a soluble receptor fusion protein.

Targeted activity of biological agents has made them more effective and less toxic treatment options. In 2006, they became more commonly used agents than cytotoxic therapies [4]. As a result of increased use of biologics, various adverse effects have been observed [6]. These include infusion-related reactions, cytokine release syndrome, hypersensitivity (immediate and delayed) reactions, immunodeficiency, autoimmunity, allergic/atopic disorders, crossreactivity with normal cells (e.g., acne from antiepidermal growth factor receptor), and nonimmunological side effects (e.g., depression from interferons) [7]. Immediate onset hypersensitivity reactions with monoclonal antibodies will be discussed in this article.

\section{Clinical presentations}

Hypersensitivity reactions (HSRs) are classified according to time of onset as immediate ( $<1 \mathrm{~h}$ of drug administration) or delayed ( $1 \mathrm{~h}$ to 1 week after drug administration) and to the mechanism involved: allergic or non-allergic [8]. Delayed-type HSRs to biologics including rash, vasculitis, serum sickness like symptoms, Stevens-Johnson syndrome (SJS), and toxic epidermal necrolysis (TEN) have been reported [9-11]. Immediate onset HSRs include acute infusion-related reactions, cytokine release syndrome (CRS), and IgEmediated hypersensitivity reactions. They may be clinically indistinguishable from each other, and mixed-type reactions may be observed.

Acute infusion-related reactions and CRS can occur at first administration with common clinical features such as fever, pruritus, flushing, tachycardia, hypertension, dyspnea, nausea, vomiting, and syncope. On the other hand, IgE-mediated reactions require repeated exposure to the antigen $[8,12 \bullet \bullet$, 13•]. The most common HSR due to a monoclonal antibody is an acute infusion-related reaction; nevertheless, the underlying mechanism of these reactions is currently unknown. In addition to common symptoms, patients may display atypical clinical features such as rigor, back pain, and abdominal pain. Mild-to-moderate infusion reactions can be managed by 
premedication with corticosteroids, antihistamines and antipyretics, and slowing infusion rate $[14 \bullet 15]$.

Cytokine release syndrome is a disorder characterized by nausea, headache, tachycardia, hypotension/hypertension, rash, and/or hypoxia. CRS is caused by the release of cytokines especially TNF- $\alpha$, interferon- $\gamma$, and interleukin- 6 from monocytes, macrophages, cytotoxic T cells, and NK cells [16, 17]. Not only monoclonal antibodies but also non-protein-based cancer drugs, stem cell transplantation, graft-versus-host disease, and severe viral infections can cause CRS. The manifestation of CRS varies from flu-like symptoms to severe lifethreatening conditions such as renal failure, cardiac dysfunction, and capillary leakage with pulmonary edema. In some cases, death has been reported. The respiratory system is commonly affected, and the manifestations vary from cough and tachypnea to acute respiratory distress syndrome depending on the severity of reaction $[18,19]$. Treatment of CRS depends on the severity of the reaction. For mild and moderate reactions, management includes slowing the infusion rate (after a temporary break) and premedication with corticosteroids and acetaminophen. Severe reactions are usually clinically indistinguishable from IgE-mediated reactions, and management is similar to anaphylaxis [13•].

\section{IgE-mediated hypersensitivity reactions}

IgE-mediated hypersensitivity reactions occur as a result of basophil and mast cell activation. The binding of antigen-specific IgE to FceRI receptor on the surface of basophils and mast cells leads to the release of mediators such as histamine, platelet-activating factor, cysteinyl leukotrienes, tryptase, and prostaglandins. Systemic effects of the mediators are responsible for clinical findings, cutaneous flushing, headache, airway obstruction, and hypotension. In addition, elevated serum levels of these mediators, especially tryptase, are helpful for the differential diagnosis of IgE-mediated reactions [20]. The most severe form of IgE-mediated hypersensitivity is anaphylaxis, defined as severe life-threatening systemic hypersensitivity reactions. The clinical manifestations depend on the organ system involved: cutaneous, respiratory, gastrointestinal, or cardiovascular system [21].

Up to now, more than 400 anaphylaxis cases induced by biological agents, including mAbs, cytokines, and enzymes, have been reported [22]. Commonly, IgE-mediated reactions to drugs occur after a sensitization phase with multiple exposures to the drugs. A few exceptions have been reported on anaphylaxis during first administration of mAbs. Preexisting IgE antibodies against galactose- $\alpha$-1,3-galactose (alpha-gal) have been identified as the underlying cause of first-dose anaphylaxis for cetuximab and infliximab. Alpha-gal is an oligosaccharide which is found in mammalian meats and FC fragment and Fab portion of cetuximab heavy chain, Fc fragment of infliximab, and a few other monoclonal antibodies. Lone star tick (Amblyomma americanum) bitten patients develop IgE antibodies to alpha-gal. Therefore, first dose of cetuximab or infliximab may cause anaphylaxis [23, 24]. Bueren et al. showed that only alpha-gal present on the Fab domain of cetuximab 
binds to alpha-gal-specific IgE antibodies of sensitized patients in vitro and no binding to alpha-gal-specific IgE of other alpha-gal containing monoclonal antibodies, basiliximab, palivizumab, zalutumumab, panitumumab, and abatacept or the Fc fragment of cetuximab [25]. However, theoretically; patients sensitized to alpha-gal may experience anaphylaxis to the first dose of biologics which have alpha-gal motif in Fc fragments. Two cases of anaphylactic reactions during the first dose of basiliximab have been reported, but their alpha-gal IgE levels were unavailable [26]. In addition to that, first-dose anaphylaxis to omalizumab has been reported due to polysorbate which is a solubilizing agent used in drugs to stabilize emulsions $[27,28]$. Other additives of biological agents such as mannitol, albumin, polysorbate 80, latex, papain, and trometamol may have antigenic potential [29].

Emergency management of anaphylactic reactions to monoclonal antibodies is the same as in anaphylaxis from other causes. After evaluation of the airway, breathing, circulation, and removal of the allergen, which means immediate cessation of the infusion, first-line treatment is intramuscular administration of adrenaline. If the patient has no response to adrenaline within 5-10 min, intramuscular adrenaline should be repeated. Secondline and third-line treatments consist of oxygen, adequate position, nebulized adrenaline, nebulized beta-2-agonist, intravenous normal saline, corticosteroid, and antihistamine administration depending on the clinical presentations of the patient $[6,21]$. Serum tryptase levels should be obtained 30-120 min after the reaction to differentiate anaphylaxis from infusion-related reactions and cytokine release syndrome. The severity of organ involvement such as cardiovascular symptoms is correlated with higher serum tryptase levels. Although elevated serum tryptase levels from baseline suggest mast cell activation, in some cases of anaphylaxis, serum tryptase levels may be within the normal range [30, 31].

If the patient has experienced anaphylaxis to monoclonal antibodies, skin tests with the culprit agent should be performed 4-6 weeks after the reaction. Timing is critical because mast cells are temporarily unresponsive to the allergen in skin tests for the period of 4 weeks. Although skin tests are the most sensitive and specific in vivo tests, no available standardized protocols have been defined for biological agents except adalimumab, etanercept, infliximab, and omalizumab [32]. Furthermore, different skin testing concentrations for these mAbs and abatacept, bevacizumab, brentuximab, cetuximab, natalizumab, pertuzumab, rituximab, tocilizumab, and trastuzumab have been published in case reports (Table 1) [15, 33-41].

If the clinical features do not strongly suggest an IgE-mediated reaction, serum tryptase level after 60 min of the reaction is within normal range, and SPTs with culprit drug are negative, the patient may receive the drug with graded challenge doses. Graded challenge should be performed with 1/10th of the total drug dose for initial administration. Also, starting with 1/100th of the total dose has been reported as an additional step before $1 / 10$ th of the therapeutic dose. If the patient tolerates initial doses, the rest of the drug could be given after a 30- 
Table 1. Suggested skin testing concentrations for mAbs

\begin{tabular}{|c|c|c|c|c|}
\hline & $\mathrm{SPT}(\mathrm{mg} / \mathrm{mL})$ & IDT $(\mathrm{mg} / \mathrm{mL})$ & IDT $(\mathrm{mg} / \mathrm{mL})$ & IDT $(\mathrm{mg} / \mathrm{mL})$ \\
\hline Abatacept [14•] & 25 & 0.025 & 0.25 & 2.5 \\
\hline Adalimumab [32] & 40 & 0.04 & 0.4 & 4 \\
\hline Bevacizumab [33] & 25 & 2.5 & 25 & - \\
\hline Brentuximab [34] & NA & 0.005 & 0.05 & - \\
\hline Cetuximab [33] & 5 & 0.5 & 5 & - \\
\hline Etanercept $[32,35]$ & 50 & 0.05 & 0.5 & 5 \\
\hline Infliximab [36] & 10 & 0.1 & 1 & - \\
\hline Omalizumab [37] & 125 & 0.00125 & 0.0125 & - \\
\hline Pertuzumab [38] & 1.6 & 0.016 & 0.16 & - \\
\hline Rituximab [8] & 10 & 0.01 & 0.1 & 1 \\
\hline Tocilizumab [39] & 20 & 0.2 & 2 & 20 \\
\hline Trastuzumab [8] & 21 & 0.21 & 2.1 & 21 \\
\hline
\end{tabular}

min interval $[8,42]$. Otherwise, desensitization with the culprit drug should be considered (Fig. 1).

Desensitization of a drug defines temporary clinical tolerance to the culprit drug. First drug desensitizations have been performed for penicillin allergy [43]. So far, antibiotics, aspirin, insulin, local anesthetics, chemotherapeutics, and biologic agents have been successfully administered with desensitization protocols $[44,45]$. If the drug is unequal or more effective and/or less toxic than alternatives or has a unique mechanism of action, desensitization is indicated for patients who have experienced type 1 or type 4 reactions (except severe cutaneous adverse reactions). Type 2 reactions (immunocytotoxic reactions), vasculitis, type 3 reactions (serum sicknesslike syndrome), and severe cutaneous adverse reactions (SJS/TEN, drug reaction with eosinophilia and systemic symptoms (DRESS), acute generalized exanthematous pustulosis (AGEP)) are absolute contraindications for desensitization [46]. For patients who have severe respiratory, cardiac, or systemic disease and experienced severe anaphylaxis (requiring intubation), desensitization should be considered after careful assessment of the risks and benefits. Also, patients taking beta-blockers or ACE inhibitors have an increased risk of severe reactions during desensitization [47].

Various successful desensitization protocols of biologic agents have been published. A commonly applied desensitization protocol for mAbs is a 12-step/3-bag protocol which has been administrated previously for beta-lactam antibiotics and chemotherapeutic agents [48, 49]. Based on the risk of reaction, 4 to 16 steps could be administered with 2 or 4

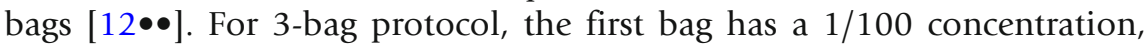




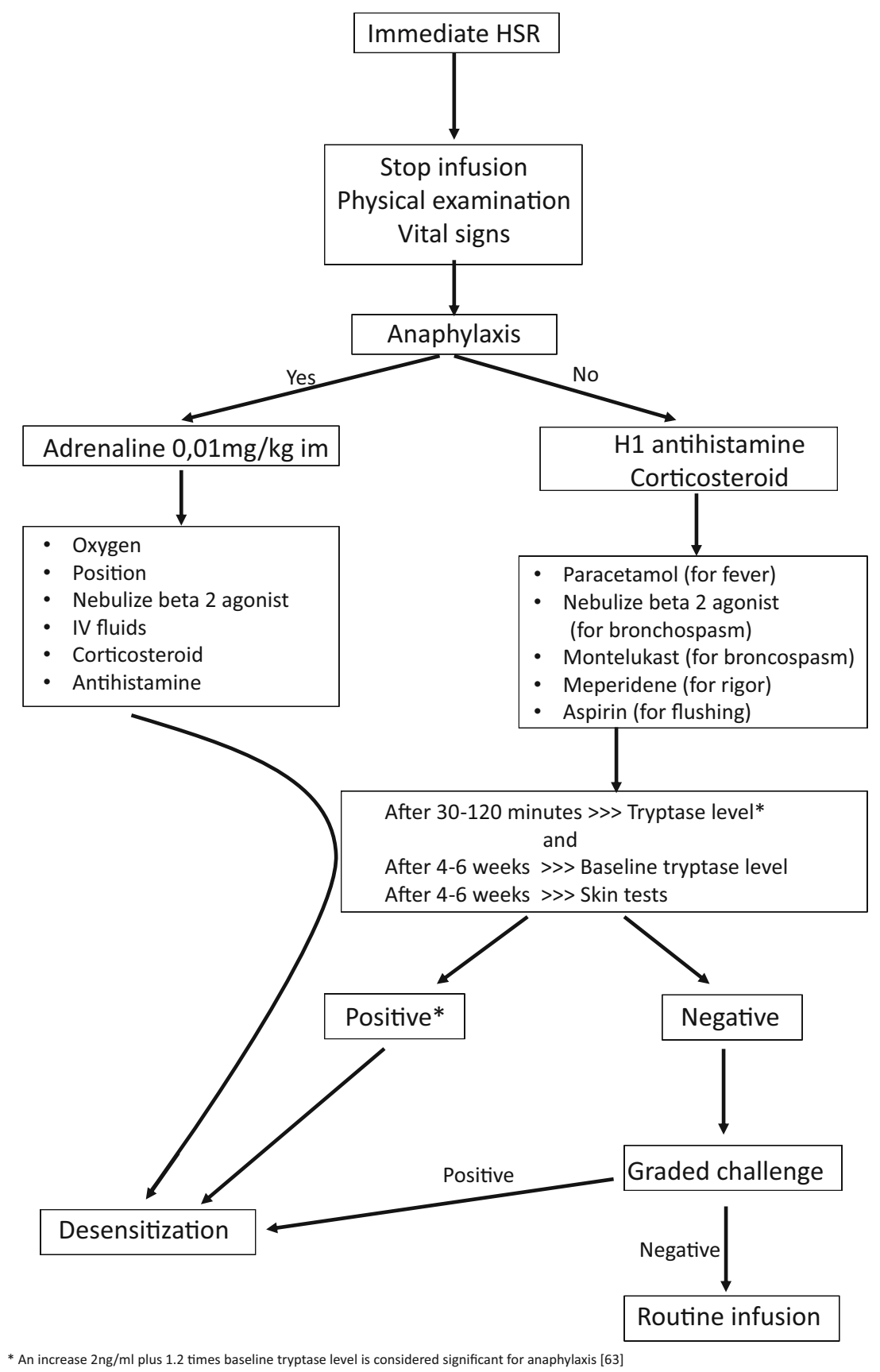

Fig. 1. The algorithm for management of hypersensitivity reactions with biologics.

and the second bag has a 1/10 dilution of the routinely recommended drug concentration. The third step's dilution is obtained by subtracting the cumulative dose given at the first eight steps from the total target dose. Each step is administered by increasing infusion rate 2-2.5-fold 
doses of the previous step with 15-min intervals. The last step extends until the complete targeted dose is administered [39]. An example of 3bag/15-step modified desensitization protocol for tocilizumab is shown Table 2 [50].

Desensitization protocols are available not only for intravenously administered agents but also for subcutaneously and orally administered biologic agents. A desensitization protocol of dasatinib, an orally administrated tyrosine kinase inhibitor, has been reported recently for delayed-type hypersensitivity reactions [51]. For adalimumab and etanercept, which are subcutaneously administered monoclonal antibodies, six or seven-step desensitization protocols have been defined. The initial dose is administrated as $1 \mathrm{~mL}$ of $1 / 100$ dilution of the routinely administrated concentration, and the next doses increase at each step as 0.5-2-fold doses of the previous one with 30min intervals [36, 52].

Brennan et al. have applied 105 desensitizations with trastuzumab, infliximab, and rituximab in 23 adult patients with rheumatologic diseases or malignancy. One hundred and four out of 105 desensitizations were successfully completed. HSR were reported in $29 \%$ of the desensitizations, and a majority of them were mild [39]. Isabwe et al. have published recently the largest report of desensitization series $(n=526)$ for mAbs with 16 different agents, including rituximab, infliximab, tocilizumab, brentuximab, trastuzumab, obinutuzumab, abatacept, ofatumumab, bevacizumab, pertuzumab, omalizumab, adalimumab, nivolumab, pembrolizumab, golimumab, and cetuximab. For intravenous mAbs, a 4-16-step/3-bag protocol is used; for subcutaneous mAbs, a 7 -step protocol was used in 104 adult patients. In $23 \%$ of desensitizations, mild to severe hypersensitivity reactions were observed. The majority of reactions were mild and occurred during the last step of

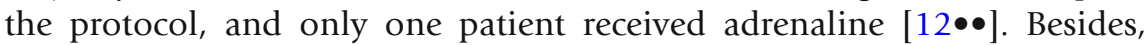
rituximab and tocilizumab desensitizations have been performed in pediatric patients. Five children who had anaphylaxis during rituximab or tocilizumab infusion underwent 84 desensitizations. Hypersensitivity was reported during only two out of 84 desensitizations, and one of them required adrenaline administration [50]. In addition to previously described mAbs, successful desensitizations have been reported for alemtuzumab, denosumab, eculizumab, and natalizumab [53-57].

$\mathrm{H} 1$ and $\mathrm{H} 2$ antihistamines (diphenhydramine/hydroxyzine/cetirizine and famotidine/ranitidine) are routinely administered $20 \mathrm{~min}$ before the initiation of all protocols. Second generation antihistamines which have longer half-lives can be given since reactions during desensitization usually occur in the last two steps $[42,58]$. Based on the severity and clinical findings of the initial reaction, additional drugs may be administered before the initiation of desensitization. Acetaminophen, nonsteroidal antiinflammatory drugs, and corticosteroids can be used to avoid fever and pain. Patients who experienced bronchospasm can take montelukast and corticosteroids. Also, montelukast and aspirin can be administered to prevent flushing. Low-dose benzodiazepines may be useful to treat anxiety during the desensitization $[12 \bullet \bullet, 39,58]$. 


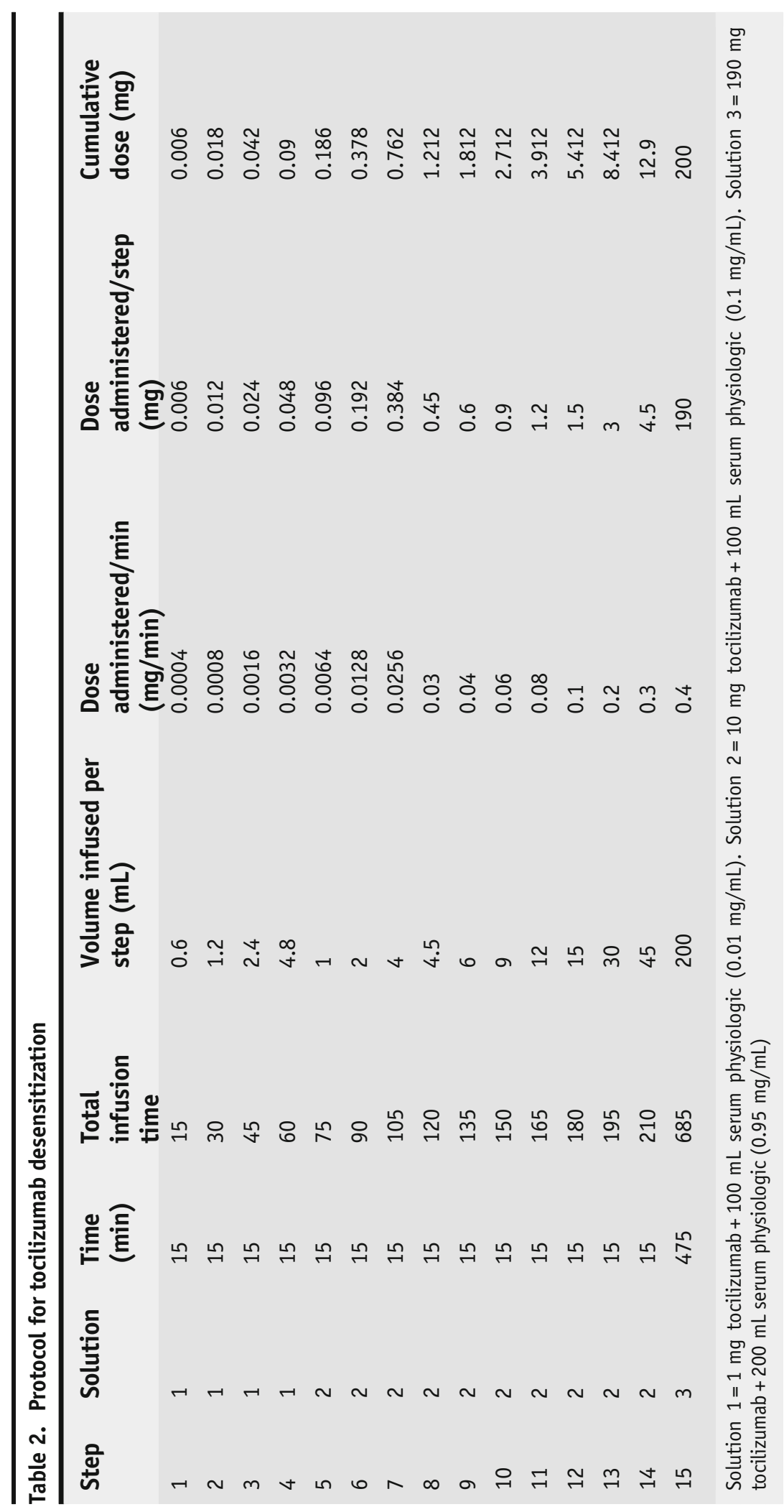


The reactions occurring during the desensitization can be treated with antihistamines, corticosteroids, and acetaminophen depending on the symptoms. Slowing down the infusion rate or an additional dose of antihistamine at the beginning of the previous step of the one where the reaction occurred should be performed at the following desensitizations. In spite of these procedures, if a reaction occurs during the desensitization, reducing the

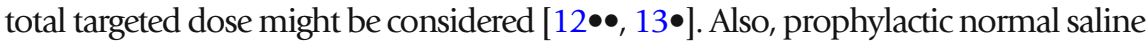
infusion (100 cc/h along the first 11 steps and $250 \mathrm{cc} / \mathrm{h}$ along the last step) can be

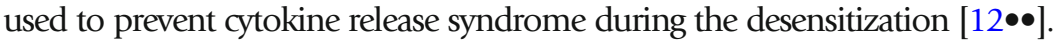

Monoclonal antibodies have the potential to stimulate immune responses due to their high molecular weight, presence of murine epitopes (chimeric mAbs), or conformationally changed neoepitopes (humanized mAbs) [14•]. Although humanization of mAbs reduces the potential of immunogenicity, generalized urticaria and anaphylaxis have been reported with the fully human mAbs canakinumab and adalimumab, respectively [59,60].

The underlying disease is an important factor for developing HSRs. Antirituximab antibodies develop more frequently in patients with systemic lupus erythematosus than in those with lymphoma [15]. In addition to that, it was shown that infliximab-related reaction rate is higher in patients who have rheumatoid arthritis than in patients who have seronegative spondyloarthritis and vasculitis [61]. These observations can suggest that patients suffering from an autoimmune disease may have an increased risk of HSR. Recently, Soyer et al. showed that renal involvement, frequent hospitalization, and exposure to more than two different biologic agents are risk factors for HSRs in children with rheumatologic diseases [59].

Antidrug antibodies (ADAs) are associated with immediate HSRs. Development of ADA to infliximab is associated with concomitant treatment with immunosuppressive agents and administration intervals. Patients who take immunosuppressors have lower incidence of ADA to infliximab, and longer intervals between infliximab administrations increase the risk of developing ADA [62]. Therefore, regular infusion regimens should be preferred to reduce HSRs to infliximab [15]. Also, cross-reactivity between TNF- $\alpha$ inhibitors is not common, so if the patient has hypersensitivity to infliximab, other TNF- $\alpha$ inhibitors such as etanercept or adalimumab may be safe alternative treatment options [31].

\section{Conclusions}

As a result of antibody engineering technologies, biologic agents have become more widely used therapeutic agents for rheumatologic diseases, cancers, and other chronic inflammatory diseases. Their complex structures and content of variable amounts of foreign regions may lead to HSRs. Although anaphylaxis is not the most common form of HSR, it may limit the clinical usage of biologic agents. Acute management of anaphylaxis to biologics is similar to that applied to other causes of anaphylaxis, but subsequent administration of the drug remains as a problem to be 
solved. If the drug is first-line treatment option or more effective than other drugs, desensitization can be performed under supervision of an experienced allergist. Nevertheless, further research is needed to understand the underlying mechanisms of hypersensitivity reactions to increase safety and efficacy of biologics.

\section{Compliance with Ethical Standards}

Conflict of Interest

Aysegul Akarsu declares that he has no conflict of interest. Ozge Soyer declares that he has no conflict of interest. Bulent Enis Sekerel declares that he has no conflict of interest.

Human and Animal Rights and Informed Consent

This article does not contain any studies with human or animal subjects performed by any of the authors.

\section{References and Recommended Reading}

Papers of particular interest, published recently, have been highlighted as:

- Of importance

- Of major importance

1. Alkan SS. Legends of allergy/immunology: Georges Kohler and the discovery of monoclonal antibodies. Allergy. 2019;74(7):1412-4. https://doi.org/10.1111/ all.13798.

2. Li GN, Wang SP, Xue X, Qu XJ, Liu HP. Monoclonal antibody-related drugs for cancer therapy. Drug Discov Ther. 2013;7(5):178-84.

3. Approvals FaDAB, Year b. https://www.fda.gov/vaccinesblood-biologics/development-approval-process-cber/ 2019-biological-approvals. Accessed 11/ 11 /2019.

4. Hausmann OV, Seitz M, Villiger PM, Pichler WJ. The complex clinical picture of side effects to biologicals. Med Clin North Am. 2010;94(4):791-804, xi-ii. https://doi.org/10.1016/j.mcna.2010.03.001.

5. https://www.who.int/medicines/services/inn/Revised mAb_nomenclature_scheme.pdf. Revised monoclonal antibody (mAb) nomenclature scheme. Geneva, 26 May 2017.

6. Galvao VR, Castells MC. Hypersensitivity to biological agents-updated diagnosis, management, and treatment. J Allergy Clin Immunol Pract. 2015;3(2):17585; quiz 86. https://doi.org/10.1016/j.jaip.2014.12. 006.

7. Pichler WJ. Adverse side-effects to biological agents. Allergy. 2006;61(8):912-20. https://doi.org/10.1111/ j.1398-9995.2006.01058.x.

8. Bonamichi-Santos R, Castells M. Diagnoses and management of drug hypersensitivity and anaphylaxis in cancer and chronic inflammatory diseases: reactions to taxanes and monoclonal antibodies. Clin Rev Allergy
Immunol. 2018;54(3):375-85. https://doi.org/10. 1007/s12016-016-8556-5.

9. Lowndes S, Darby A, Mead G, Lister A. Stevens-Johnson syndrome after treatment with rituximab. Ann Oncol. 2002;13(12):1948-50. https://doi.org/10.1093/ annonc/mdf350.

10. Urosevic-Maiwald M, Harr T, French LE, Dummer R. Stevens-Johnson syndrome and toxic epidermal necrolysis overlap in a patient receiving cetuximab and radiotherapy for head and neck cancer. Int J Dermatol. 2012;51(7):864-7. https://doi.org/10.1111/j.13654632.2011.05356.x.

11. Karmacharya P, Poudel DR, Pathak R, Donato AA, Ghimire S, Giri S, et al. Rituximab-induced serum sickness: a systematic review. Semin Arthritis Rheum. 2015;45(3):334-40. https://doi.org/10.1016/j. semarthrit.2015.06.014.

$12 \bullet$ Isabwe GAC, Garcia Neuer M, de Las Vecillas Sanchez L, Lynch DM, Marquis K, Castells M. Hypersensitivity reactions to therapeutic monoclonal antibodies: phenotypes and endotypes. J Allergy Clin Immunol. 2018;142(1):159-70 e2. https://doi.org/10.1016/j.jaci. 2018.02.018.

This article describes the largest report of desensitization series $(\mathrm{n}=526)$ for mAbs with 16 different agents.

13• Picard M, Galvao VR. Current knowledge and management of hypersensitivity reactions to monoclonal antibodies. J Allergy Clin Immunol Pract. 2017;5(3):600-9. https://doi.org/10.1016/j.jaip.2016.12.001.

This article discusses commonly administerated biologic agents in detail. 
14 Khan DA. Hypersensitivity and immunologic reactions to biologics: opportunities for the allergist. Ann Allergy Asthma Immunol. 2016;117(2):115-20. https:// doi.org/10.1016/j.anai.2016.05.013.

This article describes previous 10 years articles about CSR and anpahylaxis to biologics.

15. Vultaggio A, Castells MC. Hypersensitivity reactions to biologic agents. Immunol Allergy Clin N Am. 2014;34(3):615-32, ix. https://doi.org/10.1016/j.iac. 2014.04.008.

16. SERVICES USDOHAH. National Cancer Institute Common Terminology Criteria for Adverse Events. Published: November 27, 2017;Version 5.0. https:// ctep.cancer.gov/protocolDevelopment/electronic_ applications/ctc.htm. Accessed 11/11/2019

17. Wing M. Monoclonal antibody first dose cytokine release syndromes-mechanisms and prediction. J Immunotoxicol. 2008;5(1):11-5. https://doi.org/10. 1080/15476910801897433.

18. Seifert G, Reindl T, Lobitz S, Seeger K, Henze G. Fatal course after administration of rituximab in a boy with relapsed all: a case report and review of literature. Haematologica. 2006;91(6 Suppl):ECR23.

19. Shimabukuro-Vornhagen A, Godel P, Subklewe M, Stemmler HJ, Schlosser HA, Schlaak M, et al. Cytokine release syndrome. J Immunother Cancer. 2018;6(1):56. https://doi.org/10.1186/s40425-0180343-9.

20. Reber LL, Hernandez JD, Galli SJ. The pathophysiology of anaphylaxis. J Allergy Clin Immunol. 2017;140(2):335-48. https://doi.org/10.1016/j.jaci. 2017.06.003.

21. Muraro A, Roberts G, Worm M, Bilo MB, Brockow K, Fernandez Rivas $M$, et al. Anaphylaxis: guidelines from the European academy of allergy and clinical immunology. Allergy. 2014;69(8):1026-45. https://doi.org/ 10.1111/all.12437.

22. Sala-Cunill A, Luengo O, Cardona V. Biologics and anaphylaxis. Curr Opin Allergy Clin Immunol. 2019;19(5):439-46. https://doi.org/10.1097/ACI. 0000000000000550.

23. Chung CH, Mirakhur B, Chan E, Le QT, Berlin J, Morse $\mathrm{M}$, et al. Cetuximab-induced anaphylaxis and IgE specific for galactose-alpha-1,3-galactose. N Engl J Med. 2008;358(11):1109-17. https://doi.org/10.1056/ NEJMoa074943.

24. Chitnavis M, Stein DJ, Commins S, Schuyler AJ, Behm B. First-dose anaphylaxis to infliximab: a case of mammalian meat allergy. J Allergy Clin Immunol Pract. 2017;5(5):1425-6. https://doi.org/10.1016/j. jaip.2017.04.044.

25. Lammerts van Bueren JJ, Rispens T, Verploegen S, van der Palen-Merkus T, Stapel S, Workman LJ, et al. Antigalactose-alpha-1,3-galactose IgE from allergic patients does not bind alpha-galactosylated glycans on intact therapeutic antibody fc domains. Nat Biotechnol. 2011;29(7):574-6. https://doi.org/10.1038/nbt.1912.

26. Sasaki H, Chikaraishi T, Furuhata S, Tsutsumi H, Miyano S, Nakano T, et al. Anaphylactic reaction after initial exposure of Basiliximab: case reports. Transplant Proc. 2007;39(10):3457-9. https://doi.org/10.1016/j. transproceed.2007.08.104.

27. Price KS, Hamilton RG. Anaphylactoid reactions in two patients after omalizumab administration after successful long-term therapy. Allergy Asthma Proc. 2007;28(3):313-9. https://doi.org/10.2500/aap.2007. 28.3003.

28. Perino E, Freymond N, Devouassoux G, Nicolas JF, Berard F. Xolair-induced recurrent anaphylaxis through sensitization to the excipient polysorbate. Ann Allergy Asthma Immunol. 2018;120(6):664-6. https://doi. org/10.1016/j.anai.2018.02.018.

29. Corominas M, Gastaminza G, Lobera T. Hypersensitivity reactions to biological drugs. J Investig Allergol Clin Immunol. 2014;24(4):212-25 quiz 1p following 25.

30. Beck SC, Wilding T, Buka RJ, Baretto RL, Huissoon AP, Krishna MT. Biomarkers in human anaphylaxis: a critical appraisal of current evidence and perspectives. Front Immunol. 2019;10:494. https://doi.org/10. 3389/fimmu.2019.00494.

31. Castells MC. Anaphylaxis to chemotherapy and monoclonal antibodies. Immunol Allergy Clin N Am. 2015;35(2):335-48. https://doi.org/10.1016/j.iac. 2015.01.011.

32. Brockow K, Garvey LH, Aberer W, AtanaskovicMarkovic M, Barbaud A, Bilo MB, et al. Skin test concentrations for systemically administered drugs-an ENDA/EAACI drug allergy interest group position paper. Allergy. 2013;68(6):702-12. https://doi.org/10. 1111/all.12142.

33. Bavbek S, Ataman S, Akinci A, Castells M. Rapid subcutaneous desensitization for the management of local and systemic hypersensitivity reactions to etanercept and adalimumab in 12 patients. J Allergy Clin Immunol Pract. 2015;3(4):629-32. https://doi.org/10. 1016/j.jaip.2015.01.009.

34. Alvarez-Cuesta E, Madrigal-Burgaleta R, Angel-Pereira D, Urena-Tavera A, Zamora-Verduga M, LopezGonzalez P, et al. Delving into cornerstones of hypersensitivity to antineoplastic and biological agents: value of diagnostic tools prior to desensitization. Allergy. 2015;70(7):784-94. https://doi.org/10.1111/all. 12620 .

35. Noguerado-Mellado B, Rojas-Perez-Ezquerra P, Saenz de Santa Maria Garcia M, Rodriguez-Macias G, Tornero $\mathrm{P}$, Bartolome B. Anaphylactic shock due to brentuximab-vendotin confirmed by skin test and in vitro tests. J Allergy Clin Immunol Pract. 2017;5(5):1427-9. https://doi.org/10.1016/j.jaip. 2017.05.003.

36. Bavbek S, Lee MJ. Subcutaneous injectable drugs hypersensitivity and desensitization: insulin and monoclonal antibodies. Immunol Allergy Clin N Am. 2017;37(4):761-71. https://doi.org/10.1016/j.iac. 2017.06.001.

37. Matucci A, Pratesi S, Petroni G, Nencini F, Virgili G, Milla $\mathrm{M}$, et al. Allergological in vitro and in vivo 
evaluation of patients with hypersensitivity reactions to infliximab. Clin Exp Allergy. 2013;43(6):659-64. https://doi.org/10.1111/cea.12098.

38. Lieberman P, Rahmaoui A, Wong DA. The safety and interpretability of skin tests with omalizumab. Ann Allergy Asthma Immunol. 2010;105(6):493-5. https:// doi.org/10.1016/j.anai.2010.10.008.

39. Brennan PJ, Rodriguez Bouza T, Hsu FI, Sloane DE, Castells MC. Hypersensitivity reactions to mAbs: 105 desensitizations in 23 patients, from evaluation to treatment. J Allergy Clin Immunol. 2009;124(6):1259-66. https://doi.org/10.1016/j.jaci. 2009.09.009.

40. Gonzalez-de-Olano D, Morgado JM, Juarez-Guerrero R, Sanchez-Munoz L, Letellez-Fernandez J, MalonGimenez D, et al. Positive basophil activation test following anaphylaxis to pertuzumab and successful treatment with rapid desensitization. J Allergy Clin Immunol Pract. 2016;4(2):338-40. https://doi.org/10. 1016/j.jaip.2015.10.007.

41. Rocchi V, Puxeddu I, Cataldo G, Del Corso I, Tavoni A, Bazzichi L, et al. Hypersensitivity reactions to tocilizumab: role of skin tests in diagnosis. Rheumatology (Oxford). 2014;53(8):1527-9. https://doi.org/10. 1093/rheumatology/keu181.

42. Hong DI, Dioun AF. Indications, protocols, and outcomes of drug desensitizations for chemotherapy and monoclonal antibodies in adults and children. J Allergy Clin Immunol Pract. 2014;2(1):13-9; quiz 20. https://doi.org/10.1016/j.jaip.2013.11.007.

43. de Las Vecillas Sanchez L, Alenazy LA, Garcia-Neuer M, Castells MC. Drug hypersensitivity and desensitizations: mechanisms and new approaches. Int J Mol Sci. 2017;18(6). https://doi.org/10.3390/ijms18061316.

44. McGarry DP, Kim YM, Casselman J, Wenz R, Jhaveri D, Tcheurekdjian $\mathrm{H}$, et al. Ocular desensitization in the face of local anesthetic hypersensitivity. J Allergy Clin Immunol Pract. 2017;5(3):819-20. https://doi.org/10. 1016/j.jaip.2016.09.040.

45. Castells M. Desensitization for drug allergy. Curr Opin Allergy Clin Immunol. 2006;6(6):476-81. https://doi. org/10.1097/ACI.0b013e3280108716.

46. Cernadas JR, Brockow K, Romano A, Aberer W, Torres MJ, Bircher A, et al. General considerations on rapid desensitization for drug hypersensitivity-a consensus statement. Allergy. 2010;65(11):1357-66. https://doi. org/10.1111/j.1398-9995.2010.02441.x.

47. Giavina-Bianchi P, Aun MV, Galvão VR, Castells M. Rapid desensitization in immediate hypersensitivity reaction to drugs. Current Treatment Options in Allergy. 2015;2(3):268-85. https://doi.org/10.1007/ s40521-015-0060-2.

48. Mirakian R, Leech SC, Krishna MT, Richter AG, Huber PA, Farooque S, et al. Management of allergy to penicillins and other beta-lactams. Clin Exp Allergy. 2015;45(2):300-27. https://doi.org/10.1111/cea. 12468.

49. Castells MC, Tennant NM, Sloane DE, Hsu FI, Barrett NA, Hong DI, et al. Hypersensitivity reactions to chemotherapy: outcomes and safety of rapid desensitization in 413 cases. J Allergy Clin Immunol. 2008;122(3):574-80. https://doi.org/10.1016/j.jaci. 2008.02.044.

50. Demir S, Soyer O, Bilginer Y, Sag E, Sahiner UM, Buyuktiryaki B et al. Desensitisation overcome rituximab- and tocilizumab-related immediate hypersensitivity in childhood. Clin Exp Rheumatol 2019, in press.

51. Karaatmaca B, Aytac S, Sahiner UM, Sekerel BE, Soyer O. Successful oral desensitization with dasatinib in delayed cutaneous hypersensitivity reactions. Ann Allergy Asthma Immunol. 2019;123(2):216-7. https:// doi.org/10.1016/j.anai.2019.05.011.

52. Bavbek S, Ataman S, Bankova L, Castells M. Injection site reaction to adalimumab: positive skin test and successful rapid desensitisation. Allergol Immunopathol (Madr). 2013;41(3):204-6. https:// doi.org/10.1016/j.aller.2012.04.006.

53. Gutierrez-Fernandez D, Cruz MJ, FoncubiertaFernandez A, Moreno-Ancillo A, Fernandez-Anguita MJ, Medina-Varo F, et al. Monoclonal antibody desensitization in a patient with a generalized urticarial reaction following denosumab administration. Allergy Asthma Clin Immunol. 2015;11:29. https://doi.org/ 10.1186/s13223-015-0097-6.

54. Gutierrez-Fernandez D, Saldana-Valderas M, de la Varga-Martinez R, Foncubierta-Fernandez A, Fernandez-Anguita MJ, Fernandez-Valle MDC, et al. Hypersensitivity to alemtuzumab. A safe and effective desensitization protocol: a case report. J Oncol Pharm Pract. 2019;25(4):1016-20. https://doi.org/10.1177/ 1078155218775473.

55. Lo R, Alexander S, Moss J, Siddiqi A, Liu A. Eculizumab hypersensitivity and desensitization in a toddler with atypical hemolytic uremic syndrome. J Allergy Clin Immunol Pract. 2019;7(7):2409-10. https://doi.org/ 10.1016/j.jaip.2019.03.027.

56. Perez-Rodriguez E, Hernandez-Perez MA, MartinezTadeo JA. Successful desensitization to natalizumab using a 1-solution protocol. Ann Allergy Asthma Immunol. 2017;118(1):113-4. https://doi.org/10. 1016/j.anai.2016.10.009.

57. Ribizzi G, Bignardi D, Farinini D, Sassos D, Gentile R, Arecco D, et al. Desensitization to natalizumab: clinical and immunological observations. Mult Scler. 2013;19(3):376-7. https://doi.org/10.1177/ 1352458512448269.

58. Sloane D, Govindarajulu U, Harrow-Mortelliti J, Barry W, Hsu FI, Hong D, et al. Safety, costs, and efficacy of rapid drug desensitizations to chemotherapy and monoclonal antibodies. J Allergy Clin Immunol Pract. 2016;4(3):497-504. https://doi.org/10.1016/j.jaip. 2015.12.019.

59. Soyer O, Demir S, Bilginer Y, Batu ED, Sonmez HE, Arici ZS, et al. Severe hypersensitivity reactions to biological drugs in children with rheumatic diseases. Pediatr Allergy Immunol. 2019. https://doi.org/10. 1111/pai.13114. 
60. Quercia O, Emiliani F, Foschi FG, Stefanini GF. Adalimumab desensitization after anaphylactic reaction. Ann Allergy Asthma Immunol.

2011;106(6):547-8. https://doi.org/10.1016/j.anai. 2011.03.014.

61. Vultaggio A, Matucci A, Parronchi P, Rossi O, Palandri F, Romagnani S, et al. Safety and tolerability of infliximab therapy: suggestions and criticisms based on wide clinical experience. Int J Immunopathol Pharmacol. 2008;21(2):367-74. https://doi.org/10. $1177 / 039463200802100214$.

62. Maggi E, Vultaggio A, Matucci A. Acute infusion reactions induced by monoclonal antibody therapy. Expert Rev Clin Immunol. 2011;7(1):55-63. https://doi.org/ 10.1586/eci.10.90.
63. Castells M. Diagnosis and management of anaphylaxis in precision medicine. J Allergy Clin Immunol. 2017;140(2):321-33. https://doi.org/10.1016/j.jaci. 2017.06.012.

\section{Publisher's Note}

Springer Nature remains neutral with regard to jurisdictional claims in published maps and institutional affiliations. 